\section{JURNAL ABDIMAS

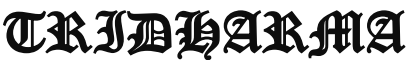

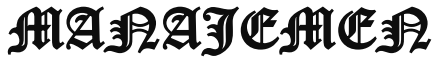

P-ISSN 2615-6849, E-ISSN 2622-3686

Jurnal ABDIMAS Vol. 2, No. 2, April 2021 Hal (19-25)

@Prodi Manajemen Fakultas Ekonomi Universitas Pamulang

Email: abdimasjurnal.unpam@gmail.com Telp: (021) 741-2566

\title{
PENDIDIKAN DAN PELATIHAN MEMBANGUN GENERASI MUDA YANG KREATIF DAN MANDIRI
}

M. Badru Zaman, Imbron, Alvin Praditya, Yuli Wahyudi, Guruh Dwi Pratama

Dosen Ekonomi Fakultas Ekonomi Universitas Pamulang

Email: dosen02589@unpam.ac.id,pradityaalvin99@gmail.com, dosen02455@unpam.ac.id, dosen02560@unpam.ac.id,dosen02563@unpam.ac.id

\begin{abstract}
ABSTRAK
Pengabdian ini berjudul Membangun Generasi Muda Yang Kompeten dan Religius. Dan berlokasi di Komunitas Arimbin (Anak Rimba Bintaro) komunitas yang sebagian besar kegiatannya berkaitan dengan dunia Pecinta Alam yang berlokasi di Pondok Pucung, Tangerang Selatan.

Tujuan pengabdian ini adalah untuk memberikan arahan dan juga bimbingan terhadap anggota Arimbin, terkait dengan pengembangan Kompetensi dan juga nilai - nilai religius individu. Metode pelaksanaan pengabdian ini dilakukan dalam beberapa tahap, yaitu. 1) Tahapan Pendahuluan; dalam tahapan ini meliputi kegiatan survei lapangan dan hubungan dengan objek lokasi pengabdian serta penyusunan rancangan kegiatan dan keluaran dari kegiatan tersebut. 2) Tahapan Sosialisasi; dalam tahapan ini tim yang sudah menyusun dan membentuk rancangan acara kemudian menyampaikan kepada pihak sekolah serta pelaksanaan beserta keluaran yang ditentukan. 3) Tahapan pelaksanaan; tahapan ini adalah pelaksanaan dari rancangan kegiatan yang telah ditetapkan.

Kesimpulan dari pengabdian ini adalah peserta (anggota Arimbin) mendapatkan serta memahami nilai-nilai religi yang dapat dipraktikan ke dalam kehidupan sehari-hari serta mengerti akan kompetensi yang dimiliki pada individu serta faktor-faktor yang dapat membuat serta meningkatkan kompetensi. Harapan dari kegiatan pengabdian ini adalah dapat membuka wawasan peserta agar bisa lebih mengembangkan diri terutama dalam hal kompetensi dan juga dapat mempraktikan nilai-nilai religi di dalam kehidupan sosial bermasyarakatKeywords: Pelatihan, Pendidikan, Cerdas Emosional, Karakter, Remaja
\end{abstract}

\section{Kata Kunci: Pelatihan, Pendidikan, Religiusitas, Kompetensi, Remaja}

\begin{abstract}
This activity is entitled "Building a Competent and Religious Young Generation" and located in the Arimbin Community (Anak Rimba Bintaro), a community whose activities are mostly related to the world of Nature Lovers, located in Pondok Pucung, South Tangerang.
\end{abstract}




\section{JURNAL ABDIMAS

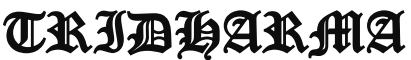

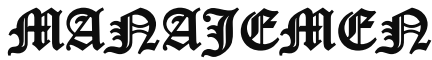

P-ISSN 2615-6849, E-ISSN 2622-3686

Jurnal ABDIMAS Vol. 2, No. 2, April 2021 Hal (19-25)

@Prodi Manajemen Fakultas Ekonomi Universitas Pamulang

Email: abdimasjurnal.unpam@gmail.com Telp: (021) 741-2566

The purpose of this service is to provide direction and guidance to Arimbin members, related to competency development and also individual religious values. The method of implementing this service is carried out in several stages, namely. 1) Preliminary stages; This stage includes field survey activities and relationships with the object of the service location as well as the preparation of activity designs and the outputs of these activities. 2) Socialization Stages; in this stage the team that has compiled and formed the program design then submits it to the school and the implementation and the specified outputs. 3) Stages of implementation; this stage is the implementation of the activity design that has been determined.

The conclusion of this service is that participants (members of Arimbin) get and understand religious values that can be practiced in everyday life and understand the competencies that individuals have and the factors that can create and improve competence. The hope of this service activity is that it can open participants' insights so that they can further develop themselves, especially in terms of competence and can also practice religious values in social life in society.

\section{Keywords: Training, Education, Religiosity, Competence, Youth}

\section{PENDAHULUAN}

Masa remaja sering dikenal dengan istilah masa pemberontakan. Pada masa-masa ini, seorang anak yang baru mengalami pubertas seringkali menampilkan beragam gejolak emosi, menarik diri dari keluarga, serta mengalami banyak masalah, baik di rumah, sekolah, atau di lingkungan rumah maupun di lingkungan pertemanannya (Unayah \& Sabarisman, 2015)

Dan dengan adanya arus globalisasi yang pesat serta kemajuan zaman dapat berdampak kepada sendi kehidupan. Tidak terkecuali kehidupan remaja (baca: generasi muda). Menurut (Reza, 2013) hal tersebut dapat memberikan dampak positif maupun negatif bagi kehidupan remaja. Remaja yang menunjukkan perilaku sesuai dengan norma dan nilai yang berlaku, maka remaja dikatakan memiliki moralitas. Sedangkan remaja yang menunjukkan perilaku bertentangan dengan norma dan nilai yang berlaku, maka remaja dikatakan melakukan tindakan amoral

Menurut Santrock (2007) dalam (Aviyah \& Farid, 2014) faktor-faktor yang mempengaruhi kenakalan remaja yaitu. (1) Identitas, (2) Kontrol diri (3) Usia, (4) Jeniskelamin, (5) Harapan terhadap pendidikan dan nilai-nilai di sekolah, (6) Proses keluarga, (7) Pengaruh teman sebaya, (8) Kelas sosial ekonomi, (9) Kualitas lingkungan sekitar tempat tinggal. Di samping faktor-faktor tersebut, ber- dasarkan temuan penelitian sebelumnya religiusitas juga merupakan salah satu faktor yang menyebabkan kenakalan remaja.

Berdasarkan dari beberapa literasi yang telah disebutkan di atas penting dalam generasi muda khususnya kepada remaja untuk selalu mempelajari serta memahami proses keagamaan serta kompetensi dimana hal tersebut diharapkan tidak hanya akan berdampak kepada perilaku individu sehari-hari tetapi juga berdampak terhadap 


\section{JURNAL ABDIMAS

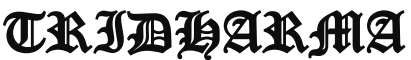

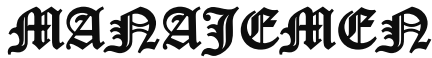

P-ISSN 2615-6849, E-ISSN 2622-3686

Jurnal ABDIMAS Vol. 2, No. 2, April 2021 Hal (19-25)

@ Prodi Manajemen Fakultas Ekonomi Universitas Pamulang

Email: abdimasjurnal.unpam@ gmail.com Telp: (021) 741-2566 lingkungan secara luas. Dalam artikel kali ini, akan dibahas mengenai kompetensi dan pentingnya memahami religiusitas serta beberapa faktor yang berkaitan dengan hal tersebut. Agar dapat dijadikan sebagai khasanah literasi dan keilmuan bagi yang ingin mengembangkan hal tersebut

\section{RUMUSAN MASALAH}

Dengan melihat latar belakang yang telah diutararkan di atas, kami berinisiatif untuk melakukan kegiatan Pengabdian Kepada Masyarakat agar dapat membantu dalam hal ini generasi muda (pelajar) untuk dapat mengenali kreatifitas dan kemandirian yang diharapkan dapat memberikan dampak khususnya di bidang kehidupan sosial pada umumnya;

1. Bagaimana remaja dapat berpikir kreatif?

2. Bagaimana remaja dapat mandiri?

\section{TUJUAN PELAKSANAAN}

Adapun tujuan dari kegiatan Pengabdian Kepada Masyarakat adalah:

1. Agar remaja dapat berpikir kreatif.

2. Agar remaja dapat mandiri.

\section{TINJAUAN PUSTAKA}

\section{Generasi Muda (Milennial)}

Generasi muda saat ini adalah generasi milennial yang diartikan oleh Yuswohady (2016) dalam (Najoan, 2020) generasi yang lahir dalam rentang waktu awal tahun 1980 - 2000. Disebut generasi millennial dikarenakan merekalah generasi yang hidup dalam di pergantian millennium dan secara bersamaan dengan teknologi digital yang merasuk ke dalam sendi kehidupan sosial.

Lebih lanjut, (Najoan, 2020) dengan mengutip pendapat Kilber (2014) menambahkan bahwa karakteristik yang terbentuk pada generasi millennial adalah kecanduan internet, percaya diri dan harga diri yang tinggi, lebih terbuka dan bertoleransi terhadap perubahan, memperlihatkan gaji dan pemberian pengakuan terhadap individu; jadwal kerja yang flexibel.

Sedangkan menurut Sugiharti (2014) dalam (Hariyanti, 2017) Generasi Muda Muslim saat ini adalah bagian dari net generation yaitu sebuah generasi yang merupakan sebuah komunitas cyberspace yang paling dinamis dan menjadi aktor yang aktif membangun interaksi dan memanfaatkan jejaring dalam dunia maya karena net generation tumbuh besar dalam konteks akselerasi perkembangan teknologi informasi yang luar biasa cepat. Pada dasarnya net generation merupakan generasi technoliterate, di mana mereka memiliki ketergantungan yang tinggi pada teknologi informasi dalam menjalankan aktivitas hariannya.

Masa Remaja;

Menurut Hurlock (1999) dalam (Unayah \& Sabarisman, 2015) ciri - ciri masa remaja sebagai berikut;

1. Masa remaja sebagai periode yang penting, karena perkembangan fisik, mental yang cepat dan penting dan adanya penyesuaian mental dan pembentukan sikap, nilai dan minat baru 


\section{JURNAL ABDIMAS

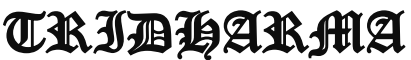

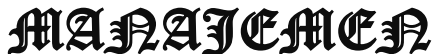

P-ISSN 2615-6849, E-ISSN 2622-3686

Jurnal ABDIMAS Vol. 2, No. 2, April 2021 Hal (19-25)

@ Prodi Manajemen Fakultas Ekonomi Universitas Pamulang

Email: abdimasjurnal.unpam@gmail.com Telp: (021) 741-2566
2. Masa remaja sebagai periode peralihan, adanya suatu perubahan sikap dan perilaku dari anak-anak ke menuju dewasa

3. Masa remaja sebagai periode perubahan, karena ada 5 perubahan yang bersifat universal yaitu perubahan emosi, tubuh, minat dan pola perilaku, dan perubahan nilai

4. Masa remaja sebagai usia bermasalah, karena pada masa kanak-kanak masalah- masalahnya sebagian besar diselesaikan oleh guru dan orang tua sehingga kebanyakan remaja kurang berpengalaman dalam mengatasi masalah

5. Masa remaja sebagai masa mencari identitas, karena remaja berusaha untuk menjelaskan siapa dirinya, apa peranannya

6. Masa remaja sebagai usia yang menimbulkan ketakutan, karena adanya anggapan stereotip budaya bahwa remaja adalah anak-anak yang tidak rapih, yang tidak dapat dipercaya dan cenderung merusak, menyebabkan orang dewasa harus membimbing dan mengawasi.

7. Masa remaja sebagai masa yang tidak realistik. Karena remaja melihat dirinya sendiri dan orang lain sebagaimana yang diinginkan dan bukan sebagaimana adanya terlebih dalam cita-cita

8. Masa remaja sebagai ambang masa dewasa, karena remaja mulai memusatkan diri pada perilaku yang dihubungkan dengan orang dewasa

\section{KREATIF}

Menurut Munandar (2012) dalam (Nurjanah, 2015) berpikir kreatif adalah kemampuan untuk melihat bermacammacam kemungkinan penyelesaian terhadap suatu masalah, dimana penekanannya adalah pada kuantitas, ketepatgunaan dan keanekaragaman jawaban.

(Juniarso, 2020) mengungkapkan bahwa berpikir kreatif merupakan kemampuan seseorang untuk menciptakan ide-ide baru dan mengimplementasikannya untuk memecahkan masalah. Seseorang yang mempunyai kemampuan berpikir kreatif akan menunjukkan rasa ingin tahu yang besar, aktif bertanya, mencoba sesuatu, kepercayaan dirinya meningkat, dan berusaha melakukan pengalaman baru. Berpikir kreatif akan menjadikan seseorang terbiasa berpikir kritis dengan intuisinya, berimajinasi, dan mengungkapkan ide baru yang menakjubkan. Menurut (Wahyuddin, 2016) kreativitas diperlukan pada setiap bidang kehidupan. Ia diperlukan untuk mendesain sesuatu, meningkatkan kualitas hidup, mengkreasi perubahan, dan menyelesaikan masalah.

Sedangkan Slameto (2010) dalam (Blegur \& Tlonaen, 2017) mengeksplor terma-terma (istilah) yang sama maknanya dengan berpikir kreatif, yaitu antara lain;

\section{Imajiner.}

2. Berpikir asli 


\section{JURNAL ABDIMAS

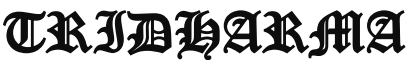

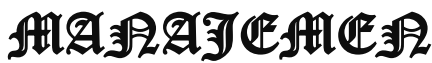

P-ISSN 2615-6849, E-ISSN 2622-3686

Jurnal ABDIMAS Vol. 2, No. 2, April 2021 Hal (19-25)

@ Prodi Manajemen Fakultas Ekonomi Universitas Pamulang

Email: abdimasjurnal.unpam@gmail.com Telp: (021) 741-2566

\section{Berpikir Divergen,}

Sedangkan (Raehan, Arizona, \& Bahtiar, 2020) mengutip pendapat dari Munandar (2009) memberikan pernyataan bahwa indikator kemampuan berpikir kreatif, antara lain;

1. Berpikir lancar (fluency)

Kemampuan untuk menghasilkan banyak ide yang keluar dari pemikiran seseorang secara cepat

2. Berpikir luwes (flexibility)

Kemampuan untuk memproduksi sejumlah ide, jawabanjawaban atau pertanyaan-pertanyaan yang bervariasi, dapat melihat suatu masalah dari sudut pandang yang berbedabeda, mencari alternatif atau arah yang berbeda-beda, serta mampu menggunakan bermacammacam pendekatan atau cara pemikiran

3. Berpikir orisinil (originality)

Kemampuan untuk mencetuskan gagasan dengan cara-cara yang asli, tidak klise dan jarang diberikan kebanyakan orang

4. Berpikir terperinci (detail) Kemampuan dalam mengembangkan gagasan dan menambahkan atau memperinci suatu objek, gagasan atau situasi

\section{MANDIRI}

Dalam UU Sisdiknas menurut (Masriah, Sukestiyarno, \& Susilo, 2015) salah satu karakter yang disebutkan dalam menentukan kemajuan suatu bangsa adalah karakter mandiri, yang didefinisikan sebagai sikap dan perilaku yang tidak mudah untuk tergantung dengan orang lain dalam menyelesaikan tugas - tugas.

Sedangkan (Hendrawan \& Sirine, 2017) mengartikan sikap mandiri sebagai sebuah tindakan atau reaksi seseorang yang di lakukan terhadap situasi tertentu dan bisa menentukan apa yang dicari dalam kehidupannya.

Ada beberapa indikator yang dapat digunakan untuk mengukur sikap mandiri seseorang menurut Paulina dkk (2012) dalam (Hendrawan \& Sirine, 2017), yaitu.

1. Pengambilan inisiatif

2. Mengatasi rintangan lingkungan

3. Memperbaiki kepribadian

4. Kepuasan kerja

5. Mandiri dalam mengerjakan tugas

\section{METODE PELAKSANAAN}

Metode pelaksanaan kegiatan ini dilakukan dalam 3 (tiga) rangkaian tahapan, yaitu; Pertama tahapan Pendahuluan, Kedua tahapan Sosialisasi dan Ketiga adalah tahapan Pelaksanaan.

1. Adapun tahapan Pendahuluan meliputi kegiatan survei lapangan dan hubungan dengan objek lokasi pengabdian serta penyusunan rancangan kegiatan dan keluaran dari kegiatan tersebut. 


\section{JURNAL ABDIMAS

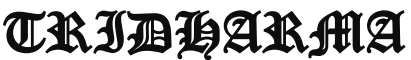

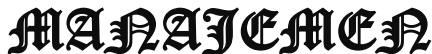

P-ISSN 2615-6849, E-ISSN 2622-3686

Jurnal ABDIMAS Vol. 2, No. 2, April 2021 Hal (19-25)

@ Prodi Manajemen Fakultas Ekonomi Universitas Pamulang

Email: abdimasjurnal.unpam@gmail.com Telp: (021) 741-2566
2. Tahapan Sosialisasi; dalam tahapan ini tim yang sudah menyusun dan membentuk rancangan acara kemudian menyampaikan kepada pihak tempat objek pelaksanaan pelaksanaan beserta keluaran yang ditentukan.

3. Dan terakhir adalah Tahapan pelaksanaan; tahapan ini merupakan pelaksanaan dari rancangan kegiatan yang telah ditetapkan

\section{HASIL DAN PEMBAHASAN}

Pengabdian Kepada Masyarakat (PKM) yang merupakan salah satu Tridharma Perguruan Tinggi adalah sesuatu yang wajib dilakukan oleh setiap Dosen tidak terkecuali Dosen dari Universitas Pamulang. Pada pelaksanann kali ini, yang menjadi objek PKM adalah komunitas (Anak Rimba Bintaro) Yaitu sebuah komunitas anak-anak muda yang beriorentasi serta mengaktulisasikan sebagian besar kegiatannya ke dalam lingkungan Pecinta Alam dan berlokasi di daerah Bintaro - Pondok Pucung - dan dilaksanakan pada tanggal $10-16$ Oktober 2020. Pelaksanaan dilakukan dengan bentuk penyuluhan dan pemberian materi yang berkaitan dengan tema yang diusung.

Dengan adanya kegiatan ini, diharapkan adanya sumbangsih baik itu dalam segi pemikiran, wawasan serta implementasi keilmuan yang dipelajari di Perguruan Tinggi bisa dibawah ke ranah praktis kehidupan

\section{KESIMPULAN DAN SARAN}

\section{Kesimpulan}

1. Peserta memahami dan mengerti akan nilai - nilai religius dalam setiap individu dan kemudian diharapkan mampu mengaplikasikannya ke dalam kehidupan sehari-hari baik secara individu maupun sosial. Hal tersebut setelah ada tanya jawab pada saat sesi jawab antar narasumber dengan peserta kegiatan.

2. Peserta memahami dan mengerti mengenai pentingnya kompetensi yang harus dimiliki oleh setiap individu untuk dapat mengatasi pelbagai problem yang ada

\section{Saran}

Dalam penyusunan acara kedepannya lebih diperhatikan terkait dengan penyesuaian materi dengan peserta pelatihan/penyuluhan agar tidak terjadi misinformasi dari peserta akibat gap peserta dengan materi. Materi yang disampaikan ditambahkan dengan video maupun narasi-narasi terkini yang berkaitan langsung dengan materi. Sehingga peserta dapat lebih memahami konteks pembahasan materi

\section{DAFTAR PUSTAKA}

Iswandi dan Saiful Amiq, 2013, "Manajemen Keuangan Keluarga" Artikel Online https://juraganmakalah.blogspot.com/2 013/03/manajemen-keuangan-keluargai.html (Diakses Hari Selasa 6 Oktober 2020)

Kasmir (2010), Pengantar Manajemen Keuangan. Edisi Kedua, Penerbit: Kencana Prenada Media Group, Jakarta. 


\section{JURNAL ABDIMAS

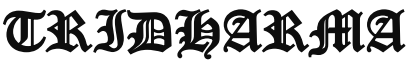

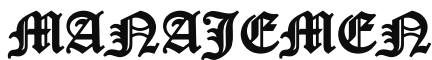

P-ISSN 2615-6849, E-ISSN 2622-3686

Jurnal ABDIMAS Vol. 2, No. 2, April 2021 Hal (19-25)

@ Prodi Manajemen Fakultas Ekonomi Universitas Pamulang

Email: abdimasjurnal.unpam@gmail.com Telp: (021) 741-2566
Love Life Daily, 2020, "Manajemen Keuangan bagi Lajang dan Keluarga Baru di Era New Normal" Artikel Onlinehttps://ilovelife.co.id/blog/manaj emen-keuangan-bagi-lajang-dankeluarga-baru-di-era-new-normal/. (Diakses Hari Selasa 6 Oktober 2020).

Gitman, Lawrence, J.(2015). Principles of Manajerial Finance. International Edition, 10th edition, Pearson Education, Baston.

Hasibuan, Malayu S.P. (2012). Manajemen Sumber Daya Manusia. Jakarta : PT.Bumi Aksra.

Pasaribu, V. L. D., Susanti, F., \& Hartuti, E. T. K. (2019). Memotivasi Siswa dan Siswi SMK Letris Indonesia di Dalam Menentukan Pilihan Untuk Melanjutkan Pendidikan Atau Bekerja Setelah Lulus Sekolah. Jurnal Pengabdian Dharma Laksana, 1(2), 161-172.

Pasaribu, V. L. D., Agrasadya, A., Shabrina, N., \& Krisnaldy, K. (2020). MENJADI ENTERPRENEUR MUDA YANG MEMILIKI JIWA LEADERSHIP UNTUK MENGHADAPI MASA DEPAN. Abdi Laksana, 1(1).

Pasaribu, V. L. D., Elburdah, R. P., Sudarso, E., \& Fauziah, G. (2020). PENGGUNAAN MANAJEMEN WAKTU TERHADAP PENINGKATAN PRESTASI BELAJAR DI SMP ARAISIYAH. Jurnal ABDIMAS Tri Dharma Manajemen, l(1).

Pasaribu, V. L. D., Sulaiman, S., Sutiman, S., Thaharudin, T., \& Purnomo, B. Y. (2020). PENGENALAN LETAK POSYANDU TERDEKAT DIKELURAHAN PISANGAN DENGAN MANAJEMEN PEMASARAN REVOLUSI 4.0 UNTUK MENINGKATKAN PENGETAHUAN MASYARAKAT LETAK DAN FUNGSI POSYANDU TERDEKAT PADA KELURAHAN PISANGAN. DEDIKASI PKM, 1(1), 105-110.

Pasaribu, V. L. D., Oktrima, B., Prabowo, B., Arianto, N., \& Haryoko, U. B. (2020). PROGAM PENDAMPINGAN DAN PENYELENGGARAAN PENDIDIKAN ANAK PADA USIA DINI TERHADAP
PRESTASI BELAJAR DILINGKUNGAN RT 020 RW 009. KEL GIRI PENI. KEC WATES. YOGYAKARTA. JURNAL LOKABMAS KREATIF, 1(1), 71-75.

\section{DOKUMENTASI FOTO KEGIATAN}
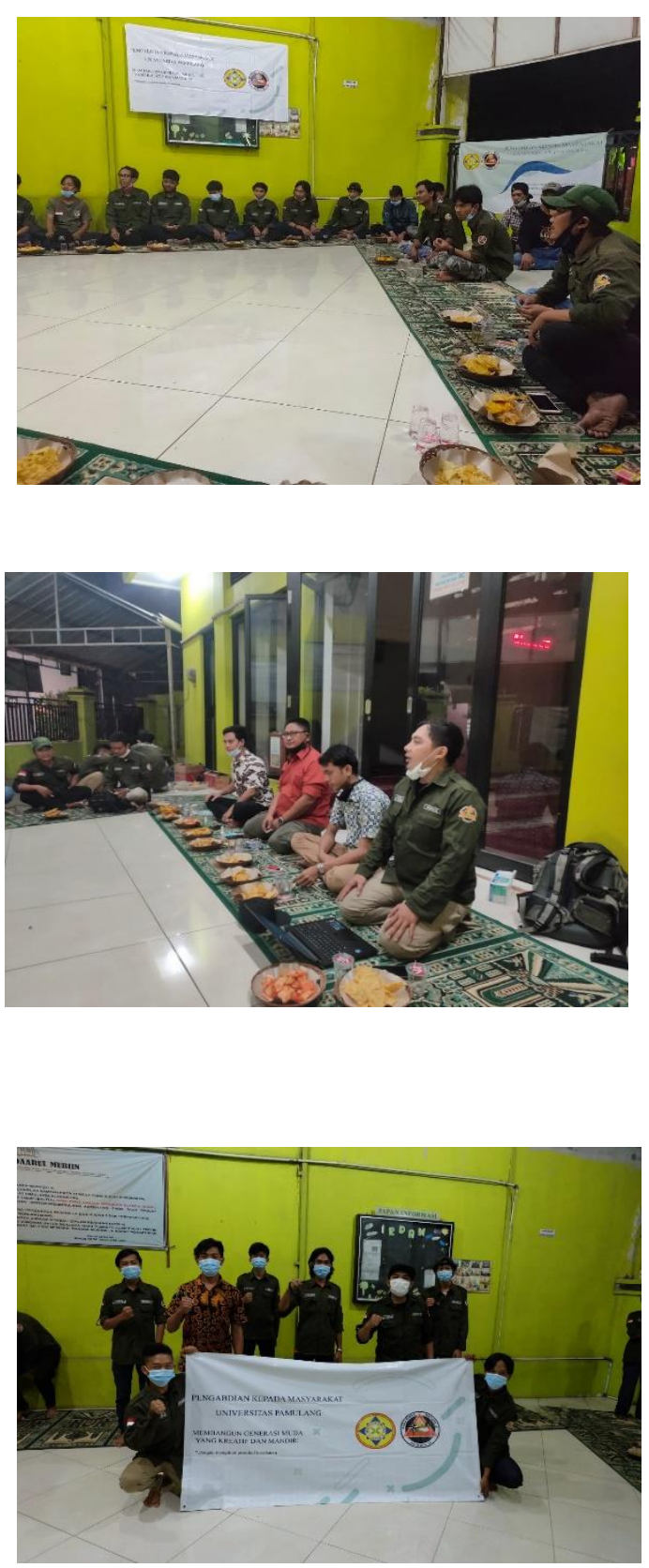